\title{
The Effect of Different Fertilizer on Aphids Populations
}

\author{
Tufail Ahmed Wagan Basit Ali Morio Nusrat Hussain Abbasi Aakash Sario \\ Shahid Hussain Phulpoto Irum Gul Jessar \\ Department of Plant Protection, Sindh Agriculture University SZABAC Dokri, Pakistan
}

\begin{abstract}
Hordeum vulgare is one of the most important cereal crop plants and severe attacked by aphid. Present study was designed to evaluate the effect of different fertilizers and their combination on aphid infestation in barley. Three different fertilizer i. e. urea, DAP, and urea+DAP were applied to three different barley fields after 25 days of germinations. Data was recorded after every 10 days. Results showed that lowest pest population was recorded in urea+DAP field.
\end{abstract}

DOI: $10.7176 /$ ALST/77-01

Publication date: January $31^{\text {st }} 2020$

\section{Introduction}

Barley (Hordeum vulgare L.) belongs to the family Gramineae and is one of the most important cereal crop plants in the world. It can be grown in any type of soil with any climatic condition (Akar et al. 2004). In ancient time, the barley was cultured for human feeding purpose, whereas in modern world, it also cultivated for human and animal feed, in addition also used for manufacture of beer (Hockett and Nilan 1985). In many countries the output from barley is not ideal as it was recommended; the main factors of low yield are insect pest infestation and improper usage of fertilizer with wrong time. Fertilizers are the basic need of plant, but improper application of fertilizers especially nitrogen would lead to a significant increase in the number of herbivorous pests (Hassan 1991). Nearly 20 insect species infest barley, the most commonly pest species are aphids, cereal leaf beetle thrips and wireworms. Russian wheat aphid (Diuraphisnoxia) is a pest of wheat, barley and other cereal grains. Russian wheat aphid damages plants by injecting salivary toxins and can severely reduce yields if not controlled. Russian wheat aphid is adapted to semi-arid dry-land climates with an average annual rainfall less than $600 \mathrm{~mm}$. keeping the about infestations of Russian wheat aphid in winter growing crops, the present study was designed to observe the effect of three different fertilizers such as Urea, DAP and Urea+DAP on aphid population on barley crop.

\section{Material Method}

The experiment was conducted at Shaheed Zulfiqar Ali Bhutto Agricultural college Dokri located at latitude $27.3743^{\circ} \mathrm{N}$ Longitude $68.0967^{\circ} \mathrm{E}$ and has an elevation of Altitude 39 meters.

Experimental Design

A local barley cultivar was sown in three different seed beds of $1 \times 2$ meters on December, $25^{\text {th }}$ in rows. The row to row distance was $15 \mathrm{~cm}$. all germination were complete in seven days. Three different treatment were designed: treatment-1 Fifty grams of Urea; treatment-2 fifty grams of DAP; and treatment-3: 25grams of Urea and 25grmas of DAP were applied to three different plots after 25 days of sowing. No any pesticide was applied for pest control. Crop was cleaned from weeds whenever it needed.

Data Recording

Data recordings were started 25 days after germination. Twenty plants were observed for aphid population in the early morning, with an interval of three days. Both adult and nymphs aphids were counted and recorded. The mean numbers of treatments were compared and analyzed using statistical program for social sciences (SPSS). All data figures were prepared using Microsoft Office Excel 2010.

\section{Result}

Aphids

There were three treatment combinations each with effect of different fertilizers dates on aphid infestations in barley there were three plots and that different fertilizer dates after fourteen days we saw the aphid infection on plots.

Result showed that aphid population appeared from the first week of observation and infested crop till the last observation in all treatments. The minimum numbers of aphid were recorded in last observation with mean number $6.11 \pm 0.22$. The peak population of aphids were recorded $33.01 \pm 0.22$ was recorded in the fourth observation (Fig. 1). 


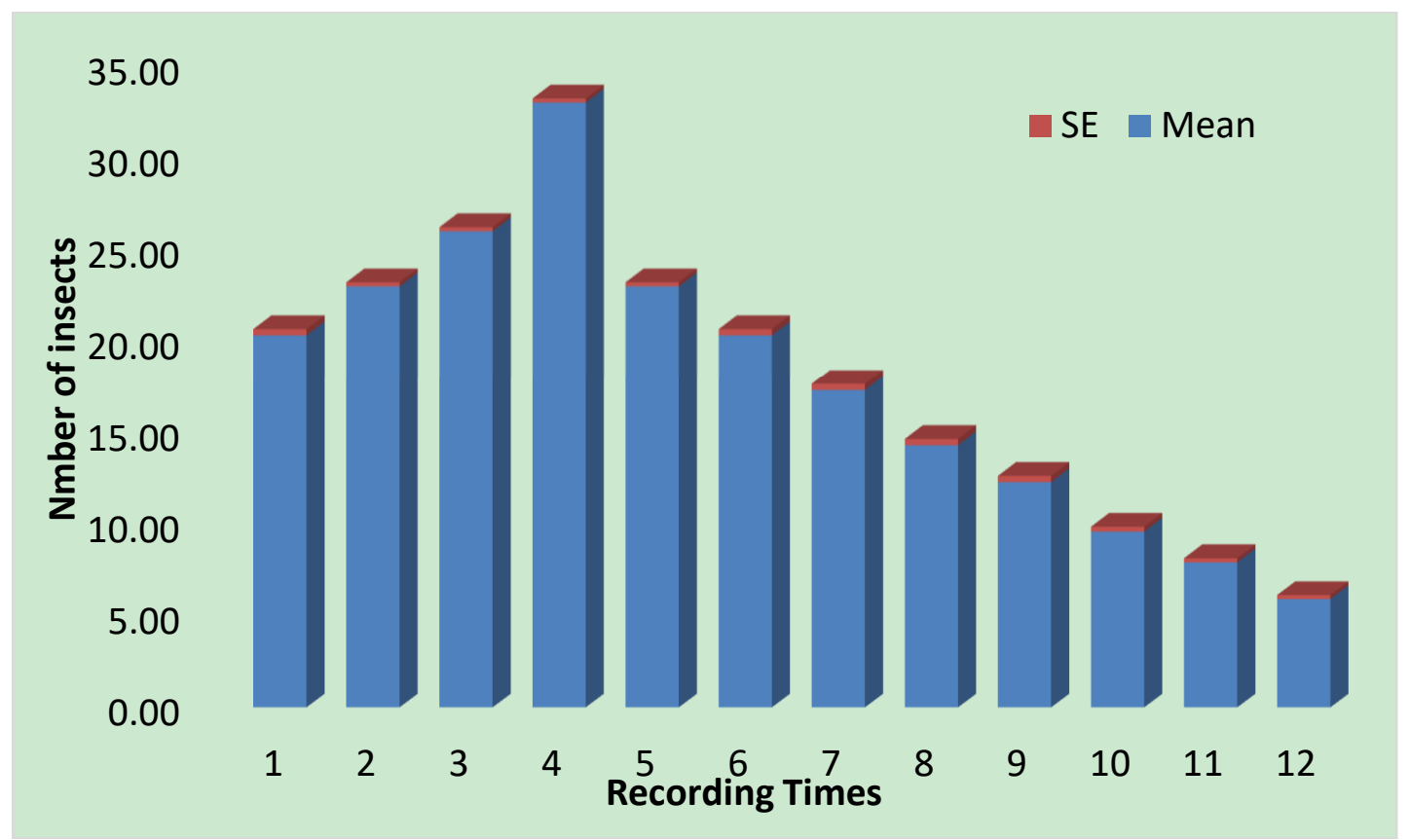

Figure 1. Mean Number of Aphids in the plot treated with Urea.

The result started that aphid population from the first week and second treatment aphid population are deferent and normal from first treatment and the minimum number of aphids were recorded in the last observation with mean number $4.03 \pm 0.22$ in treatment two and peak population of aphids were recorded $25.09 \pm 0.22$ was recorded in the fourth observation (Fig.2).

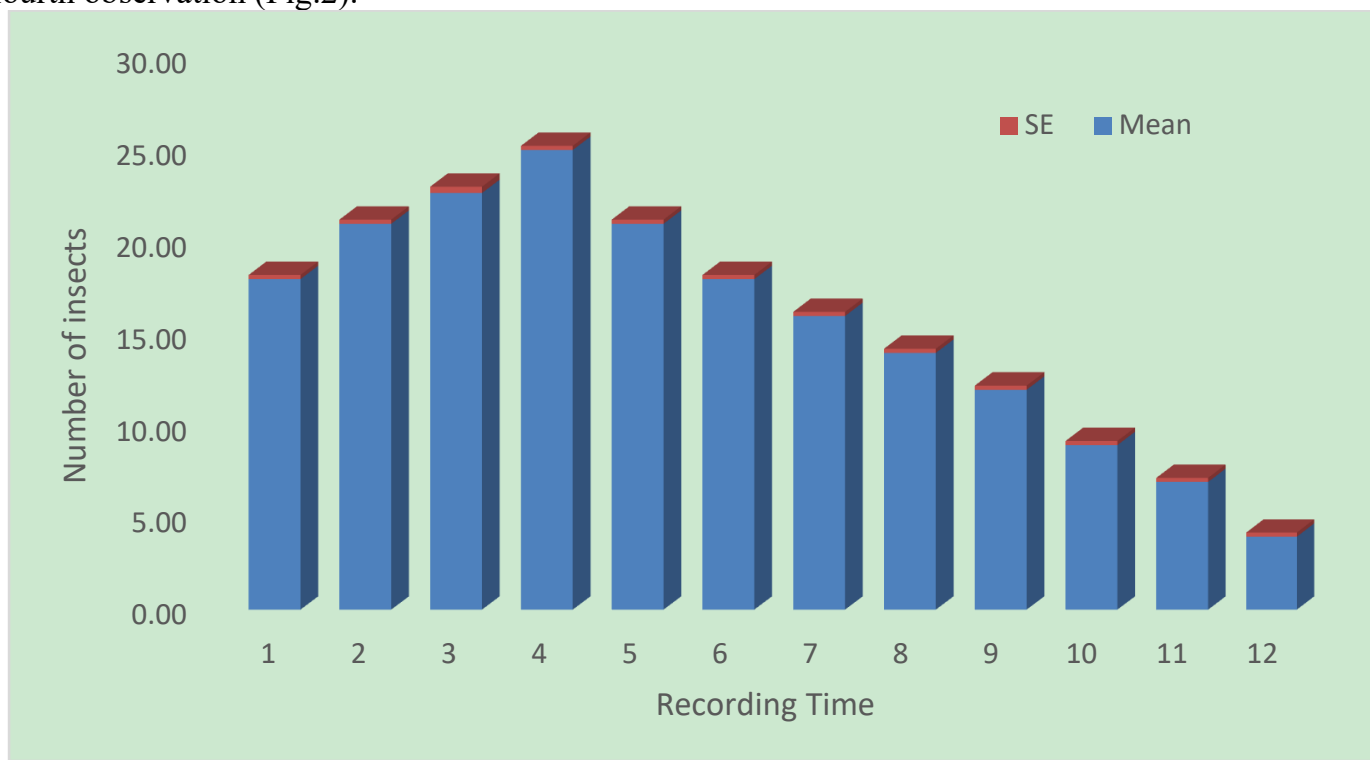

Figure 2. Mean number of Aphids in the plot treated with Urea+DAP.

The result were appeared from first week of the aphid population and the minimum of aphid were recorded in the last observation with mean number $3.02 \pm 0.22$ in the treatment three and the peak aphid population were recorded $25.01 \pm 0.22$ was recorded in the three observation (Fig.3) 


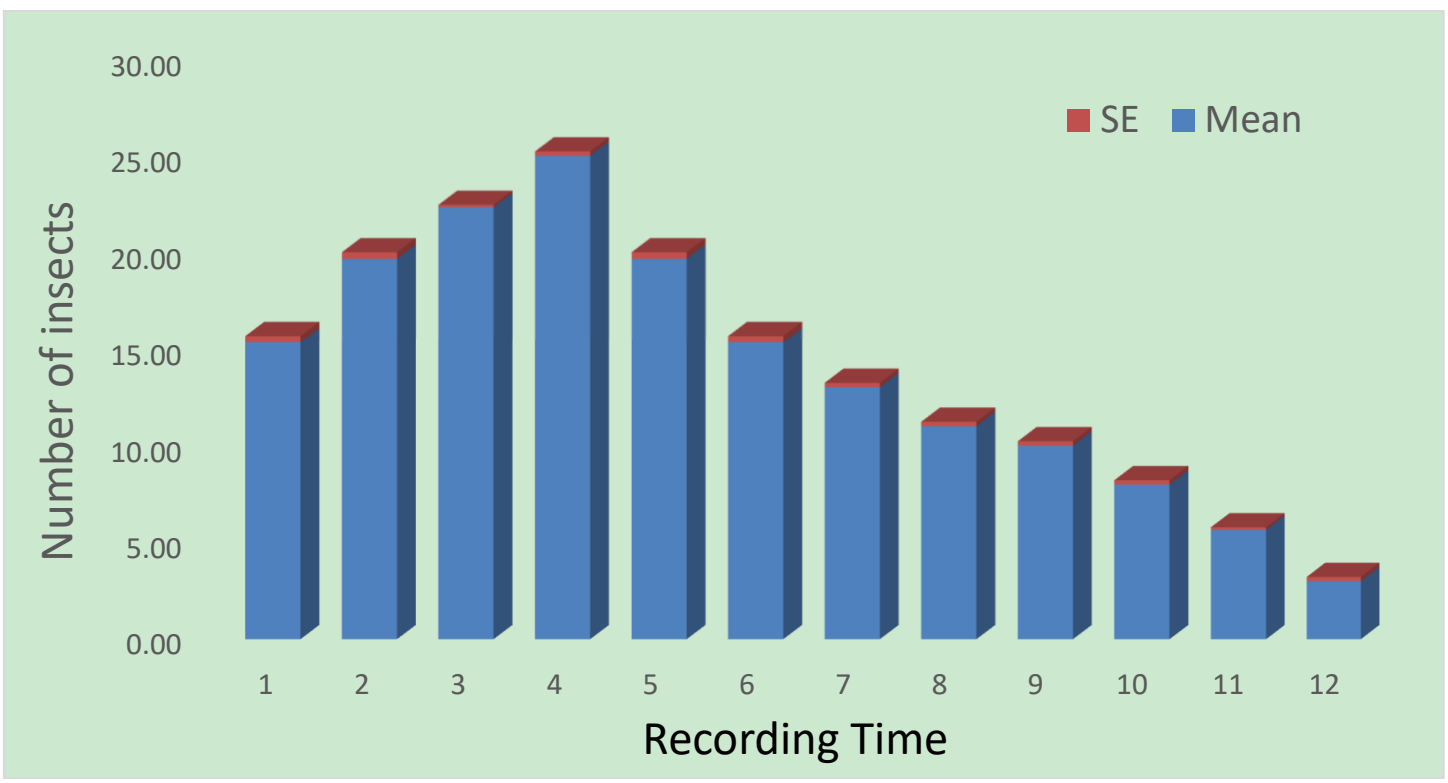

Figure 3. Mean number of Aphids in the plot treated with DAP.

In the last, the sum of all observation of all treamts were compaerd for aphid infestation. The minimum aphid population was recorded on treatment three, followed by treatment one and treatment two (Fig.4).

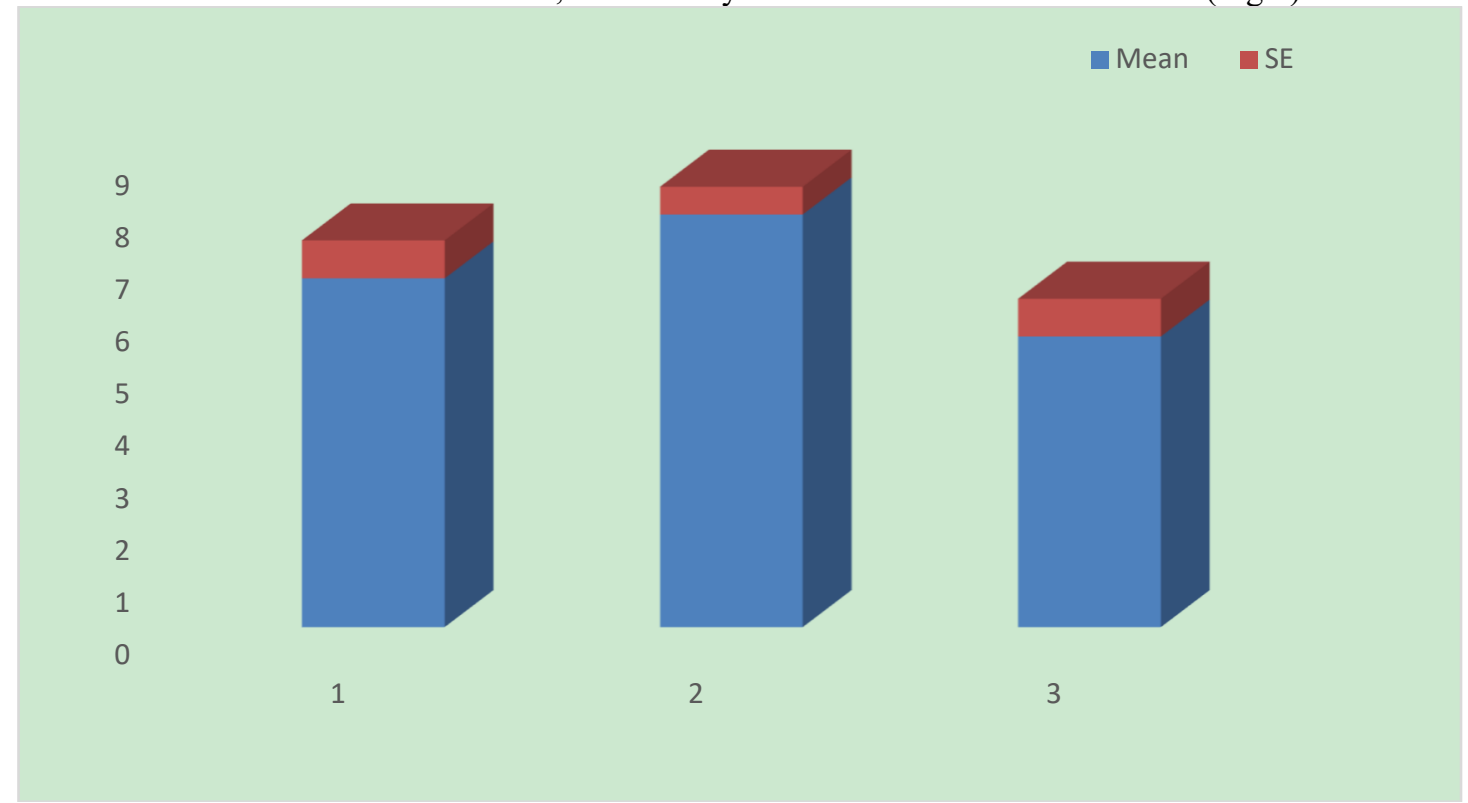

Figure 3. Over all seasonal mean number of Aphids in the plot one, two, and three.

\section{Discussion}

We observed from our results that the maximum use of urea fertilizer results the greenish crop and increase plant growth, crop attract insect pest which are the reasons of losses grain quantity and quality. The similar results of fertilizer effects on pest population was described by Sohail et al. (2007). The present study show that aphid populations appeared after the germinations and infested the crop till the harvest, aphid populations were significantly increased with increase of plant vegetative growth, similar study defined by Bindra and Mahal (1981) Predator's population shows significant correlation with aphid, the beetle observed with low numbers during first week and increased with increases the number of aphids per plant and both adult and nymph control the pest population. Same study for natural enemies were observed by Dhaunroo et al. (2018) maximum application of urea fertilizer to a crop plant can attract insect pest, and increase insect infestation. In our study we observed, balanced fertilizer can develop immune in plants against insect pest. In favorable environmental condition aphid population grow rapidly, but the natural enemies and abiotic and biotic factors can control its population (Wagan et al. 2014). From the above studies and our results confirmed that aphid can be controlled without chemical pesticides. 


\section{References}

Akar T., Avci M. and Dusunceli F. 2004. The Central Research Institute for Field Crops, Akar Organization, Ulus, Ankara, Turkey.

Bindra, O.S. and M.S. Mahal. (1981). Varietal resistance in egg plant (brinjal) (Solanum melongena L.) to the cotton jassid (Amrascabiguttulabiguttula). Phytoparasitica 9, 119-131.

Dhaunroo A.A., Khan R.A., Wagan T.A. and Nahiyoon A.A. 2018. Effect of Different Fertilizer Doses with Different Combinations on Cotton Growth and Yield. Journal of Natural Sciences Research. 8(17):1-5

Hassan I. 1991. Determination of factors inhibiting adoption of improved technology in cotton production. M.Sc. (Agric. Econ.) Thesis, University of Agriculture, Faisalabad.

Hockett E.A. and Nilan R.A. 1985. Genetic-In: Barley (ed D. RASMUSSON). Agron. Monogr. No. 26. A.S.A. Madison. p. $187-230$

Sohail, A., Habibullah, Sabir, S., \& Ch Mushtaq, A. (2007). Effect of different doses of nitrogen fertilizer on sucking insect pests of cotton, Gossypiumhirsutum, Journal of Agricultural Research, 45(1):43-48

Wagan TA, HX Hua, YP He, SA Wagan, SK Baloch (2014). Seasonal Incidence of Insect Pest and Natural Enemies on Onion Agro Ecosystem at Tandojam, Pakistan Journal. Biological. Agriculture. Healthcare (4) $27,205-212$. 